\title{
"Involved Is an Interesting Word": An Empirical Case for Redefining School-Based Parental Involvement as Parental Efficacy
}

\author{
Benjamin G. Gibbs ${ }^{1, *}$, Miles Marsala ${ }^{2}$, Ashley Gibby ${ }^{3}$, Miriam Clark ${ }^{4} \oplus$, Craig Alder ${ }^{5}$, Bryce Hurst ${ }^{6}$, \\ Dustin Steinacker ${ }^{7}$ and Brent Hutchison ${ }^{8}$ \\ Department of Sociology, Brigham Young University, Provo, UT 84602, USA \\ Palm Beach State College, Palm Beach Gardens, FL 33410, USA; marsalam@palmbeachstate.edu \\ School of Family Life, Brigham Young University, Provo, UT 84602, USA; ashley_gibby@byu.edu \\ Prevention Science, University of Oregon, Eugene, OR 97403, USA; miriamc@uoregon.edu \\ Unaffiliated, New York City, NY 10458, USA; craig.alder@citysquash.org \\ Independent Researcher, Philadelphia, PA 19148, USA; brycehurst@gmail.com \\ Utah Department of Human Services, Salt Lake City, UT 84116, USA; dsteinacker@utah.gov \\ 8 Community Action Services and Food Bank, Provo, UT 84601, USA; bhutchison@communityactionuc.org \\ * Correspondence: benjamin_gibbs@byu.edu
}

check for

updates

Citation: Gibbs, Benjamin G., Miles Marsala, Ashley Gibby, Miriam Clark, Craig Alder, Bryce Hurst, Dustin Steinacker, and Brent Hutchison. 2021. "Involved Is an Interesting Word": An Empirical Case for Redefining School-Based Parental Involvement as Parental Efficacy. Social Sciences 10: 156. https://doi.org/10.3390/ socsci10050156

Academic Editor: Nigel Parton

Received: 5 March 2021

Accepted: 15 April 2021

Published: 29 April 2021

Publisher's Note: MDPI stays neutral with regard to jurisdictional claims in published maps and institutional affiliations.

Copyright: (c) 2021 by the authors. Licensee MDPI, Basel, Switzerland. This article is an open access article distributed under the terms and conditions of the Creative Commons Attribution (CC BY) license (https:/ / creativecommons.org/licenses/by/ $4.0 /)$.

\begin{abstract}
School-based parental involvement is a common practice in the United States, and yet there is an emerging view that parents' involvement in schools may have little if any academic benefit for their children. However, such conclusions are often based on narrowly construed survey questions, such as "Did you attend PTA in the past year?". In our study, we re-examine commonly used measurements of school-based parental involvement using 130 interviews with parents and administrators across three diverse elementary schools. We compare conventional survey measures of school-based parental involvement with our own qualitative assessments of parental efficacy. Notably, we find that highly efficacious parents employed a wide range of involvement strategies, undetected by some traditional metrics of involvement (i.e., attending PTA meetings). As expected, we also find that efficacious parents were largely advantaged themselves and concentrated in advantaged schools. However, school contexts can play a powerful role in shaping the reception of parents' engagement with schools - the presence of a Spanish immersion program transformed how teachers and administrators interpreted the involvement activities of Latinx parents. Our results point to the importance of (1) recasting parental involvement as parental efficacy and (2) integrating school contexts to understand how efficacy can be more effectively encouraged and deployed.
\end{abstract}

Keywords: school-based parental involvement; parenting; elementary schools

\section{Introduction}

One key feature of American-style education is that parents are heavily involved in their child's school (Child Trends 2013), especially in the first few years. Promoted in policy and recommended in schools throughout the country (Domina 2005, e.g., Zinth 2005; Belway et al. 2009), school-based parental involvement is often viewed as a lynchpin for a child's educational success (Lareau 2011; Goodall 2018). And until recently, there has been a virtual consensus among scholars that parents with high levels of school-based involvement (i.e., parents who are involved in Parent Teacher Associations (PTAs), who communicate with their child's teacher, volunteer in the classroom, and attend parent-teacher conferences) have children with higher academic achievement than their less involved counterparts (Jeynes 2011; Park and Holloway 2017; Castro et al. 2015; Kim and Hill 2015; Shute et al. 2011). This positive relationship has been found across several domains, including literacy, mathematics, standardized tests, and grades (for reviews see Wilder 2013 and Jeynes 2011). Meta-analyses 
have shown it to be important at both the elementary and secondary school levels across racial and gender groups (Jeynes 2011).

Yet, Domina (2005) finds that the positive effects of parental involvement are only marginal when measures of parent socioeconomic status and the child's prior skills are accounted for. He argues that these findings "undermine the traditional case for increasing parental involvement in schools, suggesting that involvement is ultimately unrelated to students' academic performance" (Domina 2005, p. 246). And more recently, Robinson and Harris (2013) found that the majority of standard measures of parental involvement in schools are not statistically significant predictors of math and reading skills. Overall, Robinson and Harris conclude that parental involvement is "overrated" (Robinson and Harris 2014), and as a result, any "policy recommendations for a wholesale increase in parental involvement in children's education are misguided" (Robinson and Harris 2013, p. 221). ${ }^{1}$ It seems that parents—and especially more advantaged parents—may be expending enormous energy on behalf of their children with little to no return.

Before abandoning parental involvement as a meaningful social behavior, we argue that the concept of parental involvement needs to be developed beyond observable, frequencybased behaviors (see also Lareau 1989). Many studies measuring the relationship between involvement and achievement consist of survey items asking parents to simply identify how often they engage in certain behaviors in a given week-frequently reducing responses to dichotomized measures of "none" and "1 or more" (e.g., Domina 2005; Robinson and Harris 2013). Even Robinson and Harris concede that their measures cannot clarify "many of the qualitative aspects of involvement" (Robinson and Harris 2013, p. 221). Indeed, without a more conceptual understanding of involvement, it is difficult to assess the validity of conventional measures (Green et al. 2007; Calarco 2014a). Specifically, as Hamlin et al. (2014) argues, we need a more holistic examination of parental involvement across family cultures and social classes, and their interaction with school contexts.

For this reason, our study provides a first-of-its-kind qualitative reappraisal of the survey measurement of school-based parental involvement, comparing the precise measures employed by Robinson and Harris (2013), Domina (2005), and others with our own qualitative instruments. And while previous qualitative approaches have had the promise of a more in-depth understanding of school-based parental involvement, surprisingly, many rely on the same survey instruments employed in the quantitative literature (e.g., Chen and Gregory 2009; Desforges and Abouchaar 2003; Domina 2005; Hill et al. 2004; Pomerantz et al. 2007, but also see Lareau 2000). Thus, the focus of our study is measurement: we compare conventional survey instruments of school-based parental involvement (as developed in the Early Childhood Longitudinal Study-Kindergarten Cohort 1998-1999 (ECLS-K 98-99)) with an inductive, qualitative coding of involvement derived from over 100 parent interviews across three diverse elementary schools.

\section{School-Based Parental Involvement}

Traditional measures of school-based parental involvement often include attendance at PTA (Domina 2005; Epstein and Dauber 1991; Hill et al. 2004; Singh et al. 1995; Robinson and Harris 2013) and school activities (Pomerantz et al. 2007). Epstein (1995) seminal typology of school-based parental involvement also includes communicating and volunteering. Communication involves several different practices. These include parent-teacher conferences; reading school or classroom newsletters, emails, and announcements; and talking with a teacher when dropping off or picking up children at school (Domina 2005; Epstein 1995; Hill et al. 2004; Pomerantz et al. 2007). Volunteering is usually defined as parent volunteerism in the classroom (Domina 2005; Pomerantz et al. 2007).

Current measures of school-based parental involvement often use frequency measures (e.g., Chen and Gregory 2009; Domina 2005; Turney and Kao 2009; Park et al. 2017; Li and Fischer 2017). Some of the most common measures include involvement in PTA/PTO, attendance at parent-teacher conferences, volunteering in the classroom, volunteering or participation at other school events outside the classroom, communication with the child's 
teacher, and communication with the school principal or administrator (Chen and Gregory 2009; Desforges and Abouchaar 2003; Domina 2005; Hill et al. 2004; Pomerantz et al.

2007). Often, scales of involvement are reduced to a dichotomous measure. For example, of the 31 measures of school-based parental involvement reviewed by Robinson and Harris (2013), across two nationally representative data sets, every measure was a dichotomized version of involvement, coded as either "no" vs. "yes"; "none" vs. "once or more"; or "not in current year" vs. "once or more." This approach has practical value, allowing for researchers and policymakers to compare patterns across schools and multiple programs (Hill and Tyson 2009), but masks variation and simplifies parent's engagement with school to only observable activities.

\subsection{Redefining School-Based Parental Involvement}

There is an important body of qualitative work that utilizes participant observations and parent/administrator interviews to understand the meaning of parental involvement in schools (Cucchiara and Horvat 2009; McBride et al. 2002). López (2001) conducted interviews at four migrant-impacted schools to examine how different forms of parental involvement were encouraged. As migrants have very different strategies for deploying parental involvement, López concluded that a more holistic conceptualization of parental involvement was needed - that the concept of parental involvement needs to be expanded to consider multiple modes and motivations of involvement in schools, especially among diverse populations. Likewise, Baker (1997), using focus groups and interviews of "highly involved parents," found that parental involvement itself does not always yield returns for a child's education. Baker found that much of what constitutes effective involvement is contingent on school contexts, such as schools providing timely feedback regarding a child's academic progress and informal opportunities to receive input from parents.

Lareau's Home Advantage (Lareau 1989) and Unequal Childhoods (Lareau 2011) lay the theoretical groundwork for a more contextual understanding of school-based parental involvement. Even parents engaging in similar behaviors, such as attending parent-teacher conferences, have vastly different experiences. For instance, middle-class parents use school involvement as an opportunity to intervene in often mundane issues (e.g., child's performance in school skits and the safety of the gym), which often results in teachers' focusing more on their child. Conversely, working-class parents are more deferential and less assertive when they encounter teachers and administrators, often withholding concerns-more likely to "defer to the experts" rather than take an active role in monitoring their children's progress. Lareau's work adds up to a very different view of what involvement looks like when compared with conventional survey items that simply do not capture the intent and context of involvement close up. ${ }^{2}$

\subsection{Parental Involvement as Parental Efficacy}

Our conceptual groundwork is based on "parent academic efficacy" or what we will simplify as parental efficacy (Bandura et al. 1996; see also Harpaz and Grinshtain 2020; Tazouti and Jarlégan 2019). Parental efficacy is the confidence (and ability) parents have to overcome stress, socioeconomic burdens, and other obstacles to accomplish tasks on behalf of a child (see also Barnyak and McNelly 2009; Gubbins and Otero 2020). ${ }^{3}$ Parent efficacy is as much about parent's actual behavior as it is a parent's potential to intervene in the school and their intentions when they do. Swidler (1986) asserts that cultural practices, such as parental involvement (see Lareau 1989), represent "strategies of action" where "people may have in readiness cultural capacities they rarely employ" (p. 277). In other words, cultural resources are distinct from its activation (Lareau 1989) and parent intentions and abilities are sometimes subtle (Jeynes 2010) and not always observable.

We also view efficacy as a disposition towards problem solving that has value when it is in synch with institutional expectations and goals (Lareau 2011). When parents are viewed as intellectual resources (Jackson and Remillard 2005) or "funds of knowledge"4 (Gonzalez et al. 2006), we expect efficacy to increase. In these cases, parents "activate" 
resources to intervene in their children's education when it is needed and sanctioned by the school (Lareau 2011). Thus, the activation of school-based parental involvement is shaped not just by the needs of the child, or the interest of the parents, but by the cultural acceptance of parent-involvement strategies in a particular school. Thus, the context of the school and the experiences of the child can shape if, when, and how a parent becomes involved. As the logic of school-based parental involvement is debated (Robinson and Harris 2013), evidence rests heavily on simplified measures of school-based parental involvement. Yet, we view parental efficacy as a complex set of strategies that parents do and do not employ that are often contingent on the context of schools for its activation.

\subsection{Study Expectations}

Our purpose is compare standard metrics of school-based parental involvementattending PTA, communicating with the school, attending school activities, and volunteering in the classroom-with a more inductive, qualitative assessment of parental efficacy. To date, this kind of comparison has not been conducted. To do this, we have conducted an in-depth, open-ended assessment of involvement from those who experience it firsthand. Based on the literature above, we anticpate that some markers of school-based parental involvement will corroborate with a more holistic assessment of parental efficacy and others will not. We also anticipate that the degree to which parental involvement is 'activated' will depend on the school context and the needs of the child.

\section{Methods}

Data and Sample

We use the Parental Efficacy Project data that we collected in the fall of 2011 and winter of 2012. The data were collected to understand how parents understood their involvement in schools as their children began their first year in kindergarten. We conducted 112 in-depth interviews with parents and 18 interviews with kindergarten teachers, administrators, staff, and PTA volunteers at three public elementary schools. In spring 2012, we also administered surveys to all parents of the kindergarten children at these schools. Finally, throughout the school year, we conducted participant observations of nearly every school event. To protect our participants' privacy, we use pseudonyms for teachers, administrators, and schools. ${ }^{5}$

Examining school-based parental involvement in the kindergarten years has several advantages. Not only is the rate of school-based parental involvement at its highest level (Child Trends 2013), but this period also represents the transition of the "home child" to the "school child" (Entwisle et al. 1997). In this period, parents are actively assessing how well their child will transition from the more private sphere of home life (and preschool in many cases) into the public education system. In addition, this is a critical period of educational development, especially for fostering foundational cognitive and noncognitive skills (Heckman 2006; Duncan et al. 2007).

The schools we studied are located in the intermountain west in a state with a high commitment to parent engagement. To illustrate, in 1996 (and amended in 2000), state law required that "local school boards must adopt policies on parental involvement. Policies must provide parents with the opportunity to be actively involved in their child's education and inform them of the importance of their involvement in directly affecting the educational success of their child" (Zinth 2005, p. 17; Belway et al. 2009). Additionally, the Latinx population has increased by 30\% between 2000 and 2010 in this state. This, as we will explore, may play a role in how some teachers and Latinx parents interact.

The proximity of all three schools is less than five square miles, yet the schools are ethnically and socioeconomically diverse from one another, and each offers unique programs. Because of this contrast, each school can help us understand to what extent parent efficacy and involvement is school specific.

Our first school is Eaglewood Elementary (pseudonym) (see Figure 1). In close proximity to affluent neighborhoods, this school is $85 \%$ white and $9 \%$ Latinx (6\% other), with 
$31 \%$ of students on free or reduced lunch and only $6 \%$ of students designated as Limited English Proficient (LEP) (Keaton 2013). Part of our motivation in selecting Eaglewood was its French immersion program, which begins in the first grade. Although this does not affect the kindergarten children in our data, this program's emphasis on learning a foreign language may shape how parents with different backgrounds relate to the school.

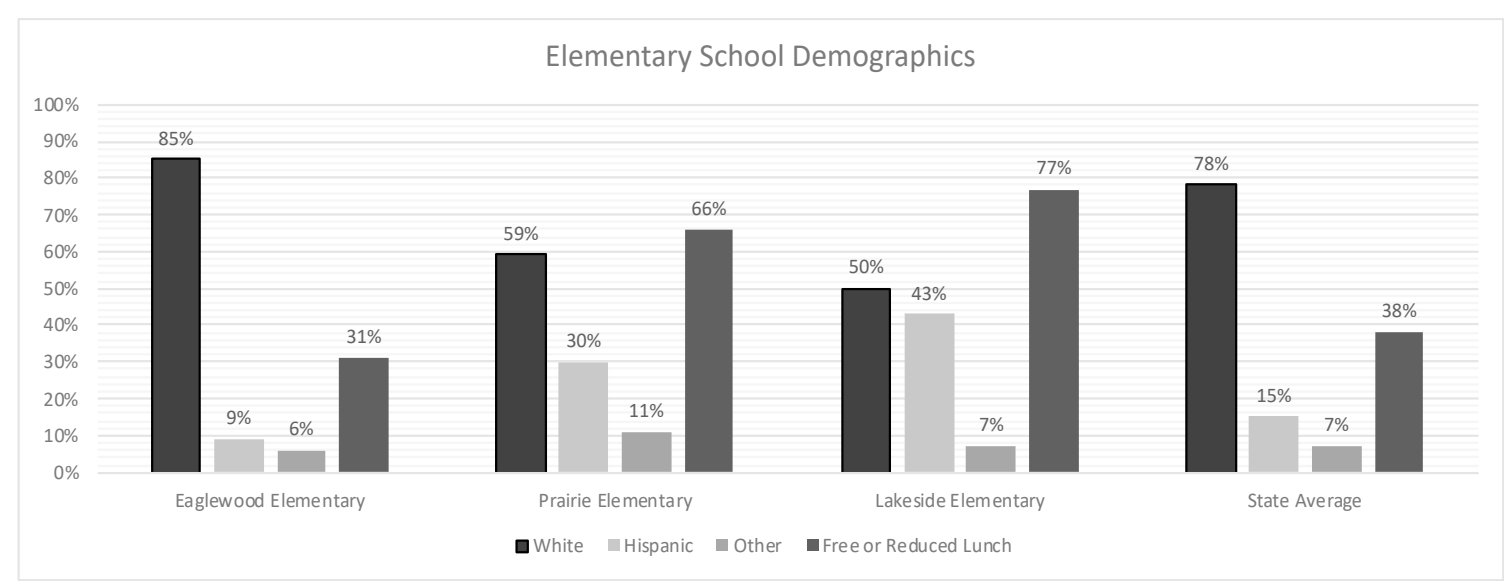

Figure 1. School Demographics of Three Study Elementary Schools. Parental Efficacy Project 2011-2012 (n=112).

Prairie Elementary is in a mixed residential area with many modest middle-class homes and a string of apartments and duplexes where a disproportionate number of Latinx families reside. Sixty-six percent of students are on free or reduced lunch. Prairie Elementary is 59\% white and 30\% Latinx, with more than $20 \%$ of students speaking English as a second language (Keaton 2013). In contrast to Eaglewood's immersion program, Prairie Elementary offers a Spanish immersion program in the first grade.

Finally, Lakeside Elementary is 50\% white and $43 \%$ Latinx (7\% other). Forty-two percent of students speak English as a second language (Keaton 2013). Lakeside does not offer a dual-immersion program. Seventy-seven percent of students are on free or reduced lunch. The surrounding neighborhoods are predominately working class.

In many ways, Prairie has demographics similar to those of Lakeside. Unlike Eaglewood, they are both designated as Title 1 schools (schools with 35\% or more students from low-income families that receive federal funding) and both Prairie and Lakeside have a fairly large Latinx population. The contrast of these two elementary schools-one with a Spanish immersion program, the other without-provides an interesting comparison we leverage to understand how context might shape school-based parental involvement.

With help from school principals and teachers, we used several methods to recruit parents. First, we contacted parents directly during child-learning assessments in the first week of school. We spoke with nearly all parents of incoming kindergartners, explained the research project, and made appointments. In addition, we sent home flyers (written in both English and Spanish) approximately one month into the school year, explaining the study and inviting participation. Parents were invited to return their flyers with their names and telephone numbers in order to arrange a time and date for an interview. To increase response rates, additional flyers were sent home each week for several weeks. We had particular difficulty recruiting parents at Lakeside Elementary due to low levels of parental engagement and for some parents, concern over their immigration status. As a result, we had to employ several methods to contact parents in this school, especially for undocumented Latinx immigrants. One successful approach was offering hot chocolate to parents as they picked up their child from school.

We collected three forms of data: in-depth interviews of parents, administrators and teachers, parent surveys, and participant observations. Of the in-depth interviews, we conducted 38 in Eaglewood Elementary, 46 in Prairie Elementary, and 28 in Lakeside Elementary. This translates to response rates in Eaglewood and Prairie that were slightly 
over $60 \%$ and around $40 \%$ at Lakeside. All interviews were digitally recorded and transcribed verbatim. At the end of parent interviews, each respondent completed a one-page demographic survey from which we collected data on their ethnic, educational, and socioeconomic backgrounds. Parents were given a $\$ 30$ gift card upon completion of the interview. Our interview team consisted of 12 members who were trained in qualitative techniques. At any given time, we had three to four interviewers on our team who were fluent in Spanish for parents that preferred to be interviewed in Spanish. Of the 112 parent interviews, 15 were conducted in Spanish (3 in Eaglewood Elementary, 4 in Prairie Elementary, and 8 in Lakeside Elementary).

Participants were interviewed according to a semi-structured format in which we developed a set of topics and questions (see Supplemental Materials: Document S1). The interviews explored the parents' interactions with the school-how they have been involved, their communication with teachers, and other related topics. Ideologies about education and parental involvement were also mentioned. For interviews involving immigrants, we also asked questions regarding past experiences with U.S. schools and discussed their experiences with education and parental involvement in their home country. Most parent, PTA, and community council volunteer interviews occurred at their homes, with only a few conducted either at the elementary school or university.

We also met with nearly all school administrators, kindergarten teachers, PTA presidents, and community-council co-chairs, using a format similar to the one developed for parent interviews (see Supplemental Materials: Document S2). Most of the 18 meetings with administrators were conducted at the school. Interviews for teachers and administrators generally covered school demographics, expectations for involvement, obstacles for parental involvement, and strategies implemented to encourage parent involvement in the classroom and school. Comments beyond these topics were encouraged.

The second form of data comes from parent surveys that were administered in the spring of 2012 (see Supplemental Materials: Document S3). We attended parent-teacher conferences and invited parents to complete a survey with an assortment of questions, many collected from national surveys regarding parental involvement. Most questions were developed from the Early Childhood Longitudinal Study-Kindergarten Cohort, a wide-ranging national study of the kindergarten class of 1998-1999. This allowed us to compare our in-home interviews with specific parent-involvement survey questions used in national data, as reported by Domina (2005) and others.

Finally, to get a better sense of the school context, we attended all school events, including assemblies, after-school parties, and PTA meetings. We observed parent interactions with teachers and administrators in these contexts. We were careful to look for variation between groups, often between Latinx and white parents. Notes were either dictated (then transcribed) or typed up shortly after each event.

\section{Measures}

We first developed themes of school-based parental involvement by rereading all parent interviews and "open coding" - generating categories related to parental involvement (Strauss and Corbin 1998). We then looked for central themes, finding the most pronounced distinctions between parents displaying high levels of parental efficacy and those displaying low levels of parental efficacy. ${ }^{6}$ We coded to integrate and refine central categories (Strauss and Corbin 1998).

In this process, we focused on behaviors that provided detailed evidence of parents interacting with schools, combined with parent philosophies for involvement. Forms of involvement were coded into the following types: communication, child problems, extracurricular activities, at-home involvement, in-class involvement, Parent Teacher Association attendance, and school-wide involvement. These categories helped us quickly identify patterns of involvement across interviews.

We developed two ways to describe the actions of parents with high and low efficacy. High parent efficacy was operationalized as parents who are assertive about their child's 
education, who actively engage in problem solving, have a sense of entitlement, are confident in their ability to resolve issues and engage in anticipatory actions that work to prevent later problems from emerging. Conversely, low parent efficacy was operationalized as parents who are often motivated by external factors, such as poor student performance or behavioral issues at school, and exhibit deference to school authorities regarding their children's academic development. We were careful to note how the context of the school may have shaped these parenting behaviors, something we calibrated from attending activities and by interviewing the child's teachers, principals and other administrators.

Overall, we interpreted high parent efficacy as proactive involvement and low parent efficacy as reactive involvement. Proactive involvement does not always mean engagement with schools in terms of frequency or behavior. Instead, we view proactive and reactive involvement as a disposition towards engagement that may or may not be activated based on the needs of the child. In this process, we developed a colloquial way to code the interviews-evidence of parents that are "on top of it" and evidence of parents who appeared to be "behind the ball." Because these categories required a confluence of evidence, no particular example or event was sufficient. Yet, generally, parents we deemed proactive often felt "responsible" for their child's education, intimately familiar with the child's school, and had a strong sense of their educational progress. These parents' actions were often in response to a parent-identified problem or concern. Conversely, parents we deemed as reactive revealed attitudes and behaviors in interviews that were in a response to either a school-identified problem, such as behavior issues, or were simply uncertain about school expectations or their child's progress.

From the transcriptions, we collected every evidence of parental efficacy and schoolbased parental involvement from the 112 parent interviews and reduced what we found to $1-2$ page summaries. We developed assessment sheets for each interviewee (see Supplemental Materials: Tables S4-S6). Two coders were assigned each interview and coded independently; then results were compared. Occasionally, coders had conflicting scores. Different values between coders were reconciled by rereading the interview and bringing each case to the larger research team for discussion. These meetings helped standardize the process and often required the group to revisit previous interviews to adjust for continuity in coding (Luker 2008). The coding sheets were reviewed at length by the research team to determine patterns, and results were ultimately combined with the survey data that we collected from parents. We also created codes for each category of involvement. With this approach, we developed a 5-point scale-high, medium-high, medium, medium-low, and low-for the purpose of synthesizing data.

To compare survey measures of school-based parental involvement with our qualitative approach, we used the following forms of involvement from our ECLS-K matched survey items: PTA involvement, communication with teacher, communication with principal or administrator, in-class volunteering, and attendance at school. We compared dichotomous measures of these behaviors with our constructed 5-point scale of schoolbased parental involvement. Our specific objective was to determine how many parents who scored as "high" based on our qualitative approach would also score "high" based on the survey metric.

For our measure of respondents' social class, we measured the parents' reported educational attainment, job position, and poverty status, in line with Condron (2009) classification (see also Calarco 2014b). Families were classified as middle/upper class if either parent had a bachelor's degree or higher, worked in an executive, managerial, or administrative position, and whose household income was above the 2011 federal poverty line (see https://aspe.hhs.gov/2011-hhs-poverty-guidelines, assessed on 12 February 2019). Families were coded as working class if neither parent had a college degree and neither parent worked in an executive, managerial, or administrative position nor had family income above the 2011 federal poverty line. Families were classified as poor if the household income fell below the 2011 federal poverty line, regardless of educational 
attainment or job position of the parents. In instances where the parents did not report their job position or education level on the survey, we gleaned information from interview data.

Although we present the following data using percentages, these are for the purpose of reflecting general patterns among a group of 112 parents and should not suggest numerical precision (Hammersley 1992). However, we feel that these percentages, although sometimes based on a small number of interviews, still reflect the qualitative tenor of our findings. We had missing data for 8 and 5 cases for child race/ethnicity and gender, respectively.

\section{Results}

\subsection{Qualitative Findings}

Table 1 reports general patterns across efficacy levels by socioeconomic status, race/ ethnicity, school, and child's gender. First, as expected, there is a clear socioeconomic pattern across efficacy levels. It is noteworthy that $82 \%$ of the parents that we code as "high" in parental efficacy were middle/upper class. Also, efficacy levels varied by race/ethnicity. A disproportionate share of our high-efficacy parents were white (91\%). By comparison, $50 \%$ of less efficacious parents were white.

Table 1. Descriptive Statistics by Level of Efficacy, Percentages Displayed, Parental Efficacy Project 2011-2012 ( $n=112)$.

\begin{tabular}{|c|c|c|c|c|c|c|}
\hline & & High & Medium-High & Medium & Medium-Low & Low \\
\hline \multicolumn{7}{|c|}{ Socio-Economic Status } \\
\hline & $\begin{array}{l}\text { Upper/Middle } \\
\text { Class }\end{array}$ & 81.8 & 65.2 & 40.0 & 33.3 & 42.9 \\
\hline & Working Class & 0.0 & 13.0 & 23.3 & 33.3 & 14.3 \\
\hline & Poor & 18.2 & 21.7 & 36.7 & 33.3 & 42.9 \\
\hline \multicolumn{7}{|c|}{ Race } \\
\hline & White & 90.9 & 79.5 & 71.4 & 40.0 & 50.0 \\
\hline & Latinx & 0.0 & 15.9 & 28.6 & 53.3 & 50.0 \\
\hline & Other & 9.1 & 4.5 & 0.0 & 6.7 & 0.0 \\
\hline \multicolumn{7}{|c|}{ School } \\
\hline & Eaglewood & 54.5 & 37.0 & 33.3 & 27.8 & 0.0 \\
\hline & Prairie & 18.2 & 47.8 & 43.3 & 38.9 & 28.6 \\
\hline & Lakeside & 27.3 & 15.2 & 23.3 & 33.3 & 71.4 \\
\hline \multicolumn{7}{|c|}{ Child's Gender } \\
\hline & Female & 30.0 & 65.1 & 51.7 & 61.1 & 57.1 \\
\hline & Male & 70.0 & 34.9 & 48.3 & 38.9 & 42.9 \\
\hline$n$ & & 11 & 46 & 30 & 18 & 7 \\
\hline
\end{tabular}

Next, we explored how efficacy levels are distributed within each school (Figure 2). The distribution of efficacy levels in each school reveals that Eaglewood and Prairie Elementary have similar distributions of efficacy, with the majority of parents at a medium-high to high level (58\% at Eaglewood and 52\% at Prairie). Only 34\% of parents at Lakeside Elementary were coded as either medium-high or high in efficacy. Lakeside represents a distribution that is flat across levels, suggesting there is not a critical mass of efficacious parents like at Eaglewood and Prairie Elementary. (Note: numbers are rounded and may not equal $100 \%$ ).

Although Prairie and Lakeside are demographically similar, we found that Prairie's Spanish immersion program encourages involvement of Latinx parents because, as one administrator put it, the program helps them feel like intellectual resources (Jackson and Remillard 2005):

As far as helping families feel valued and a part of their community, I think [the cultural programs offered] are really effective. Like I said, within our dual language program, we do have a very supportive group of Latinx parents who are, a lot of them, are very aware of their student's academic progress, I mean with exceptions of course. And they're very-they ... make sure their students 
do their homework, they're helping them with their homework, they're helping them with their studies-which is a big, which is huge-because you don't see that as much in our, in our Latinx parents that aren't in our dual language program ... With the teacher speaking Spanish, and sending emails in Spanish, and everything that comes home, they have homework in Spanish and in English, so the parents can actually read it and help. So I think that makes a big difference. (Prairie Elementary assistant principal)

While Latinx parents (and their involvement) can further the aims of Prairie Elementary, Lakeside has no such cultural programming formally developed in the curriculum.

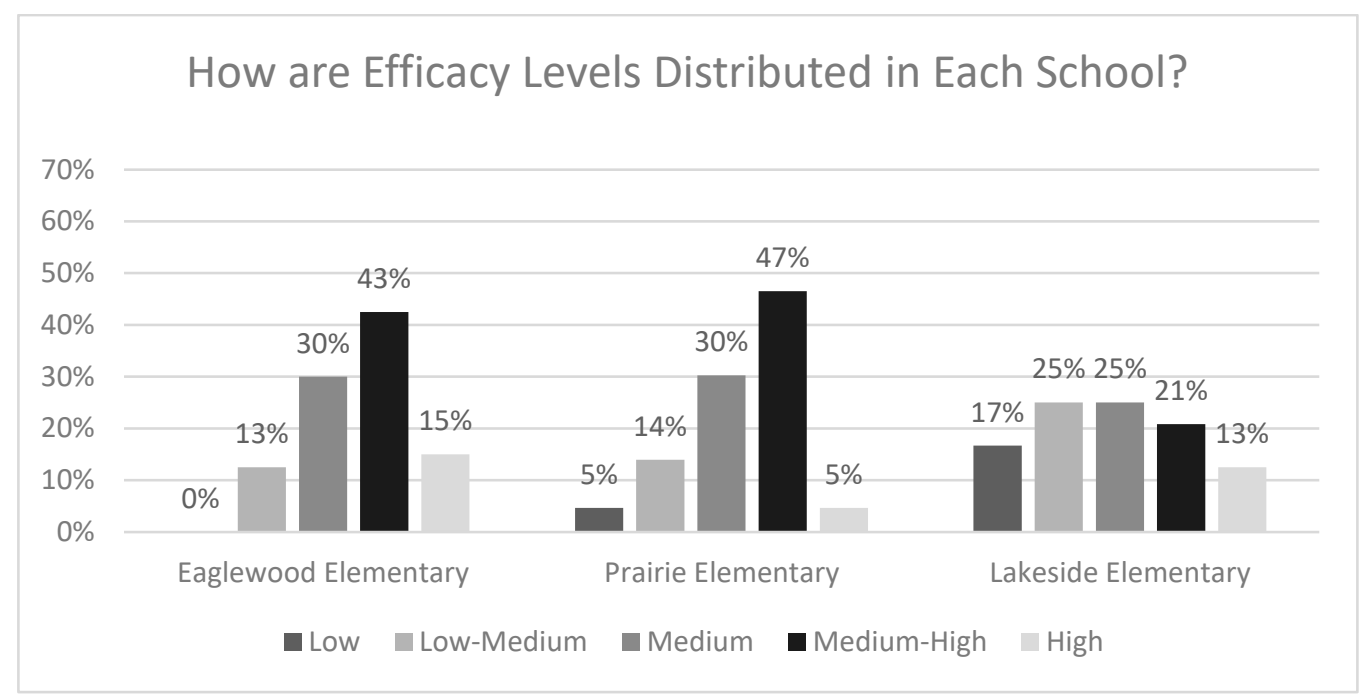

Figure 2. Distribution of Parent Efficacy Levels in Each School. Parental Efficacy Project 2011-2012 $(n=112)$.

Also, across our 38 interviews at Eaglewood Elementary, we did not interview any parents whom we coded as "low." While this could be an artifact of sample selection, we think that this illustrates just how normative high efficacy was in this school—oddly, many highly efficacious parents self-reported their involvement as low, whereas parents at Lakeside were more likely to code their involvement as high, despite having some of the lowest levels of efficacy in our study.

\subsubsection{Profile of High Parent Efficacy}

Next, to provide a profile of a highly efficacious parent, we closely examined parents we scored as "high." We found only 11 parents at this highest level (10\% of the 112 total parent interviews). A majority of these parents were middle/upper class (81\%) (see Table 1). Also, these parents were proactively involved in their child's education, with parenting behavior that often matched Lareau's description of parent "entitlement" when intervening with institutions. For example, one parent revealed a range of diverse activities employed on behalf of her child. This parent volunteered in the classroom four times a week, attended all school events (including a "fun run" while pregnant), and was a member of the PTA (although she did not attend meetings). When asked what made her choose to join the PTA, she says:

Because it's the thing to do. You should because you're a parent [she and the interviewer laugh]. I mean my kids really wanted me to because of the ice cream party situation ... . but I just join every year ... to support the school. You know ... I don't really go to the PTA meetings, I go to my kids' classes every [week]-I try to. Last year I was in here four times a week. So I try to participate in their classrooms more. I mean if the PTA needed me to do something, I would do it. 
But I try to be more hands on in the classrooms with the individual teachers and my kids.

From interviews like this, we identified behaviors and attitudes that we felt best represented high levels of efficacy, which aligned with Bandura's concept of parental academic efficacy. We found that all of our highly efficacious parents communicated with their child's teacher and exhibited problem-solving behavior. The frequency of these communications ranged from several times a week to a few times a month, but each regularly spoke with the teacher about their child and described the communication experiences to us as either "good" or "great".

Another behavior we observed was that highly efficacious parents were "problem solvers". In each case, there was a positive example of a parent seeing and anticipating a problem-either with their child in the classroom or school wide-and proactively developing a solution. Of course this means that in several cases, fewer educational problems of the child meant fewer instances of actual parental involvement. In many cases, having a successful child in a good school meant that parents with high efficacy did not need to activate their resources-a luxury that freed up parents' energy for other pursuits.

Communication with the principal varied. Examples include: "The principal knows who I am and we say 'Hi'"; "I send him emails with ideas"; and "I speak with [the principal] regularly [weekly to several times a month]". Most of these high-efficacy parents attended and/or assisted in classroom activities and/or school-wide functions. They wanted to be involved in as many aspects of the education process as possible, and while some did cite their attendance at these events as a way to support their children, many just wanted to see how "things were going at the school," see other parents, and chat with teachers and administrators. Some took a leadership role in these activities by helping out or even planning the activity.

Another behavior we observed was educational preparation and training at home. All of these parents discussed college with their children, even at the young age of 5 and 6 . Many of these parents would say things such as they "hoped" or "expected" their child to attend college while others stated bluntly that anything but college "was not an option." They also mentioned that they helped with homework, and nearly all of these parents either mentioned or implied that they are doing more to supplement their child's learning at home; for example, reading with their child daily was common. Three parents specifically mentioned that they had tried educating at home before the start of kindergarten with preschool or learning activities. Elizabeth Martin, a parent at Eaglewood Elementary, felt passionately about at-home learning:

It's my philosophy that you can go to a school that has a mediocre level of education, but as long as the parent is enhancing that at home and making sure that they're reading books with high vocabulary, that they're doing, you know, practicing their math facts in the car. I mean, there's so many things you can do as a parent to make sure that the overall environment of the home is a learning environment.

Two parents described their efforts to further their children's learning during the summer break. For example, one of these parents mentioned trying to help her daughter get ahead through programs such as e-school (an on-line schooling program provided by the district).

These parents found ways to be in the elementary school. A vast majority wanted to be in the classroom, to help the teacher, observe their child, and build social networks. One parent, who was unable to attend during classroom hours, ate either breakfast or lunch every day with her children in the school cafeteria. These parents were also very aware of school events and programs offered both inside and outside the classroom, and they talked often with other parents about the school, teachers, and programs.

A less common pattern was inclusion of their children in after-school programs or extracurricular activities (less than half of parents). When they did, activities ranged 
from sports, learning an instrument, attending the theater, going to musical productions, and travel. Given that these kindergarten children were young, this is noteworthy since extracurricular activities usually become part of a child's scheduled life in their middle and high school years (Lareau 2011; Gibbs et al. 2015). We should note that a parent's mention of extracurricular activities was not prompted by a question during the interview, so it may be more prevalent than what we report here.

Finally, the behavior least mentioned by these parents was PTA involvement. While more than half of the high-efficacy parents paid PTA membership dues, only three of the eleven considered themselves active participants. Of the three, one was the treasurer in her school's PTA and another simply attended meetings. Thus, we find that some school-based parental activities that may appear important are not necessarily valued, even among highly efficacious parents.

Philosophies of highly efficacious parents highlighted their proactive role in their child's educational development:

I'm all for public school, but I kind of view it as it's kind of my responsibility to make sure that my kids get educated, and if the school can help then great, but ultimately

I don't want to leave it all to them.

I'm the only person completely overseeing my child's education, that's my job.

I'm kind of like the middle person, but I'm also like a partner with the teacher. Like somebody who connects them, and then also somebody that teaches my child as well. Like, I can't just depend on the school.

I really believe that the parent has the number one responsibility to educate their child, they really do. That's why children are born to parents, not born into a classroom or born and then shuttled off to a classroom.

In some ways I think the schools don't expect enough ... they don't have a lot of homework really and I think they're going to be really sorry when they get to college and realize they haven't learned how to work maybe as intensely as they need to. So I always, I do try to push them a little bit more like, "'Kay, your teacher expects you to get $90 \%$ on the spelling test but let's really work for $100 \%{ }^{\prime \prime}$ ... I think helping them learn how to study at home ... helping them put in a little bit more effort than is expected so that they can really improve, instead of just, kind of go with the flow.

Highly efficacious parents are confident and in control of their child's educational future, independent of and sometimes despite their child's educational experiences at school. These parents have efficacy, even if it is not always enacted in ways that have been conventionally understood and measured as "involved".

\subsubsection{Profile of Low Parent Efficacy}

Of 112 parent interviews, there were only seven parents that we ranked "low" (the lowest ranking). Five of these parents had children enrolled at Lakeside, the school with the highest level of socioeconomic disadvantage (77\% qualified for free or reduced lunch). None of these parents were involved with the PTA or volunteered in the classroom, and very few attended school activities. Nearly $30 \%$ of these parents did have regular communication with their child's teacher, but this was usually the extent of their involvement, and in some cases, this communication was necessary to address their child's behavioral issues in class. Nearly all of these parents felt less efficacious due to some structural constraint, usually time. Compared to high-efficacy parents, some of the parents were below the poverty line ( 3 of 7), but several were college educated (see Table 1). Common statements from these parents were along the lines of, "I want to participate but [ . . . ] I can't because I don't have the time", or "I try not to sign up for anything at school because I'm working". Many 
of these parents expressed a sincere desire to be more involved, but it simply was not an option for most and therefore they felt less efficacy.

Parent philosophies of this group expressed their involvement in less proactive terms: views of involvement were often less developed and tinged with regret for not being able to be more involved. Some comments reflected self-assurances that they were doing enough despite pressure from others to do more:

I have to help [my daughter] with [homework] but yeah. They always do it in the school. She says, "I already finished my homework at school." [laughs] They always do them there.

[My main responsibility is] just being a parent ... . Just kinda like, just supervising if everything's ok with the child in school and if any conflicts come about, then solve it.

I believe in giving my children a little bit of independence and helping them to grow. I want them [sic] to be involved with his education so I'll help him here with his homework, but I try not to be the hover mom. And I have seen other mothers who are hover mothers, who always, you know, are always there, volunteering almost every day, and you know, maybe that's what their children need, but I, I guess I prefer to stand back a little bit and let them grow.

[My daughter's teacher] hasn't really sent home, you know, stuff for [her] to do, so, um, yeah. So I'm not exactly sure, you know, what kinds (sic) I need to be working on. I know I need to work on her sounds for each letter. I can do that. Anyway, I haven't done that yet ... . I just forget. [When asked why she chose not to join PTA, this parent says,] I just, I have other things. I'm trying to get ready to go back to school myself, and so I have a lot of things that I need to get done in order to get myself enrolled.

\subsection{Comparisons to Standard Metrics}

Now having described profiles of parents ranked as high and low, we now examine how well our in-depth assessments of parental efficacy compare with standard metrics. From our survey questions of school-based parental involvement, we coded the following into dichotomized variables: participation in PTA (one or more events), any communication with the child's teacher, any communication with the principal or administration, in-class or at-school volunteering (one or more times), and attendance at and/or participation in school activities (one or more times).

Figure 3 offers the most striking contrast between measures. Surprisingly, $73 \%$ of all parents that were counted as highly efficacious (50 of 56, including "high" and "mediumhigh" by our qualitative metrics) were not involved in the PTA. This result is important because Parent Teacher Organizations and Parent Teacher Associations are perhaps the most symbolic representation of school-based parental involvement. Of course part of this finding depends on how PTA involvement is assessed. Figure 4 only captures those who said they attended a PTA meeting, but there are many who sign up for the PTA, often through a sense of obligation or, in some cases, to help their child's class earn a prize.

We found that many parents would like to attend PTA but could not because of language barriers. One Spanish-speaking Latinx parent stated, "I have never participated [in PTA]. Sometimes it has been complicated because... I'm going to be honest, since I don't speak English." Another, when asked whether she was a member of the PTA, responded, "No... the language, that's the only reason. Because it's a nuisance for them to have to always be looking for someone to translate for me ...." 


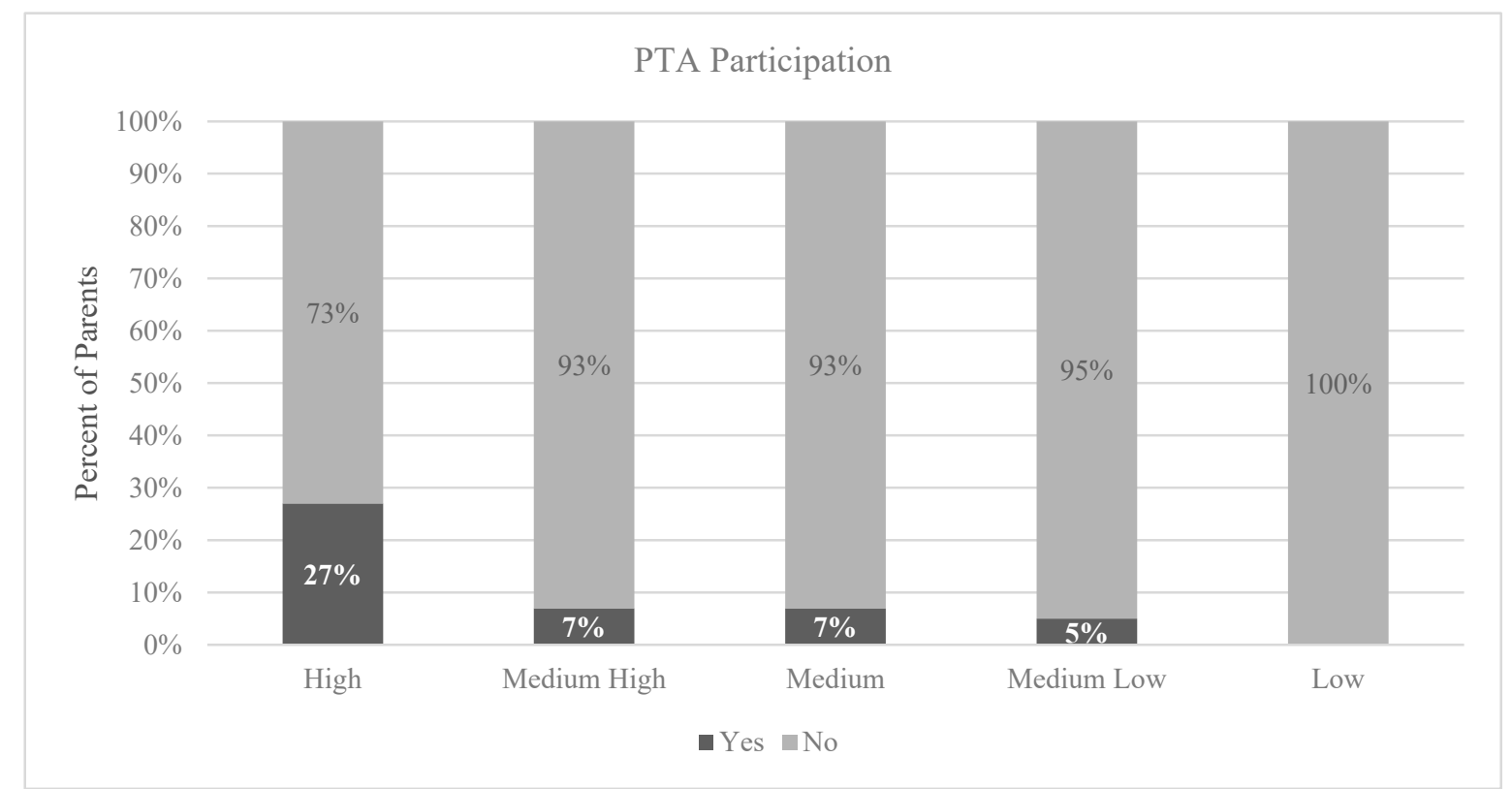

Figure 3. Percentage of Parents Efficacy in PTA across Efficacy Rankings. Parental Efficacy Project 2011-2012 ( $n=112)$.

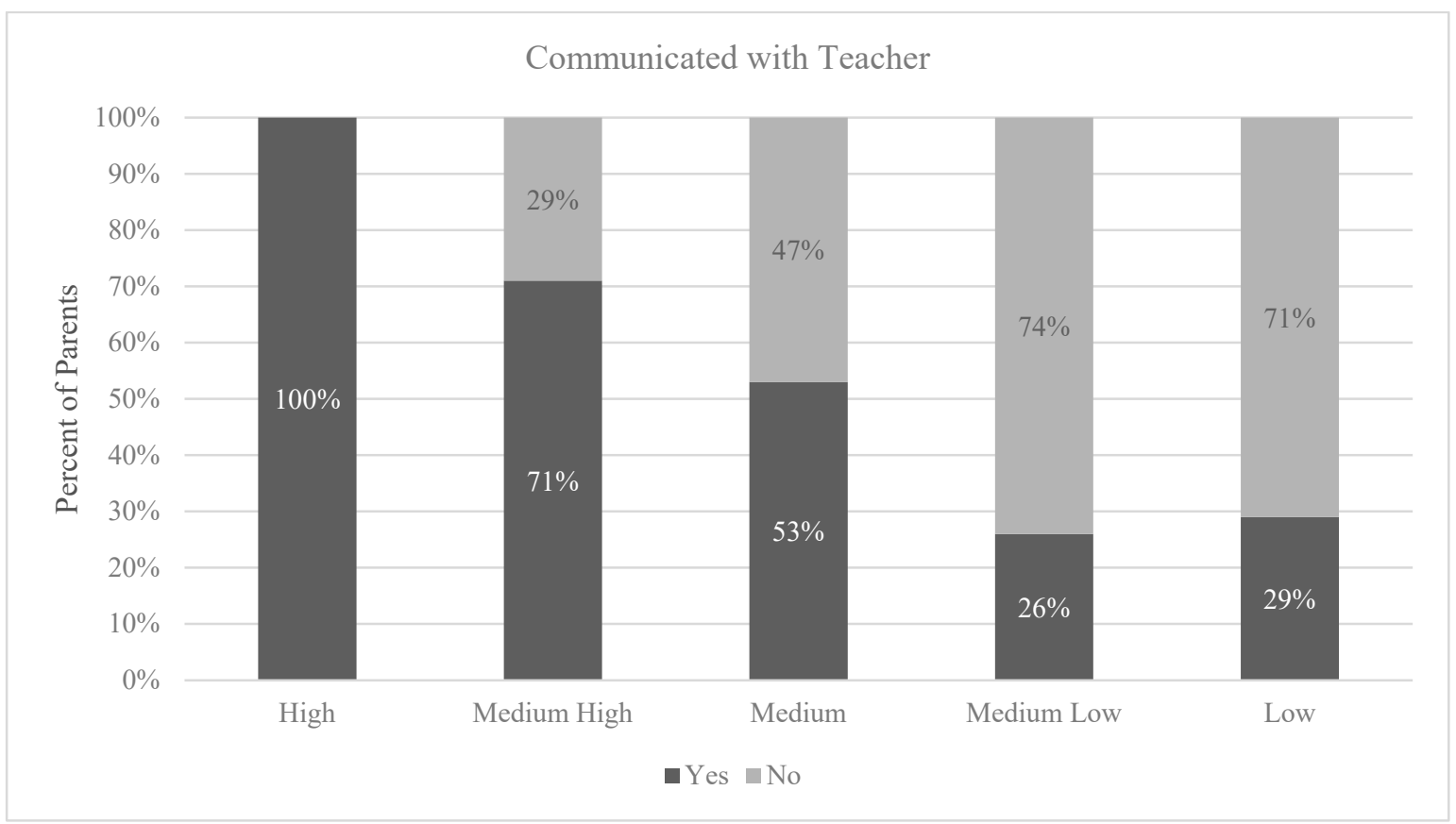

Figure 4. Percentage of Parents Who Regularly Communicate with Their Child's Teacher across Efficacy Rankings. Parental Efficacy Project 2011-2012 $(n=112)$.

For communication with the teacher (Figure 4) and the principal/administrators (Figure 5), we had somewhat unexpected results. Many of the parents at each efficacy level had communication with teachers and the principal/administrators. Even though the number of parents who had communication with school officials steadily declined across efficacy levels, approximately one-third of the parents who ranked as low still had regular communication with their child's teacher. 


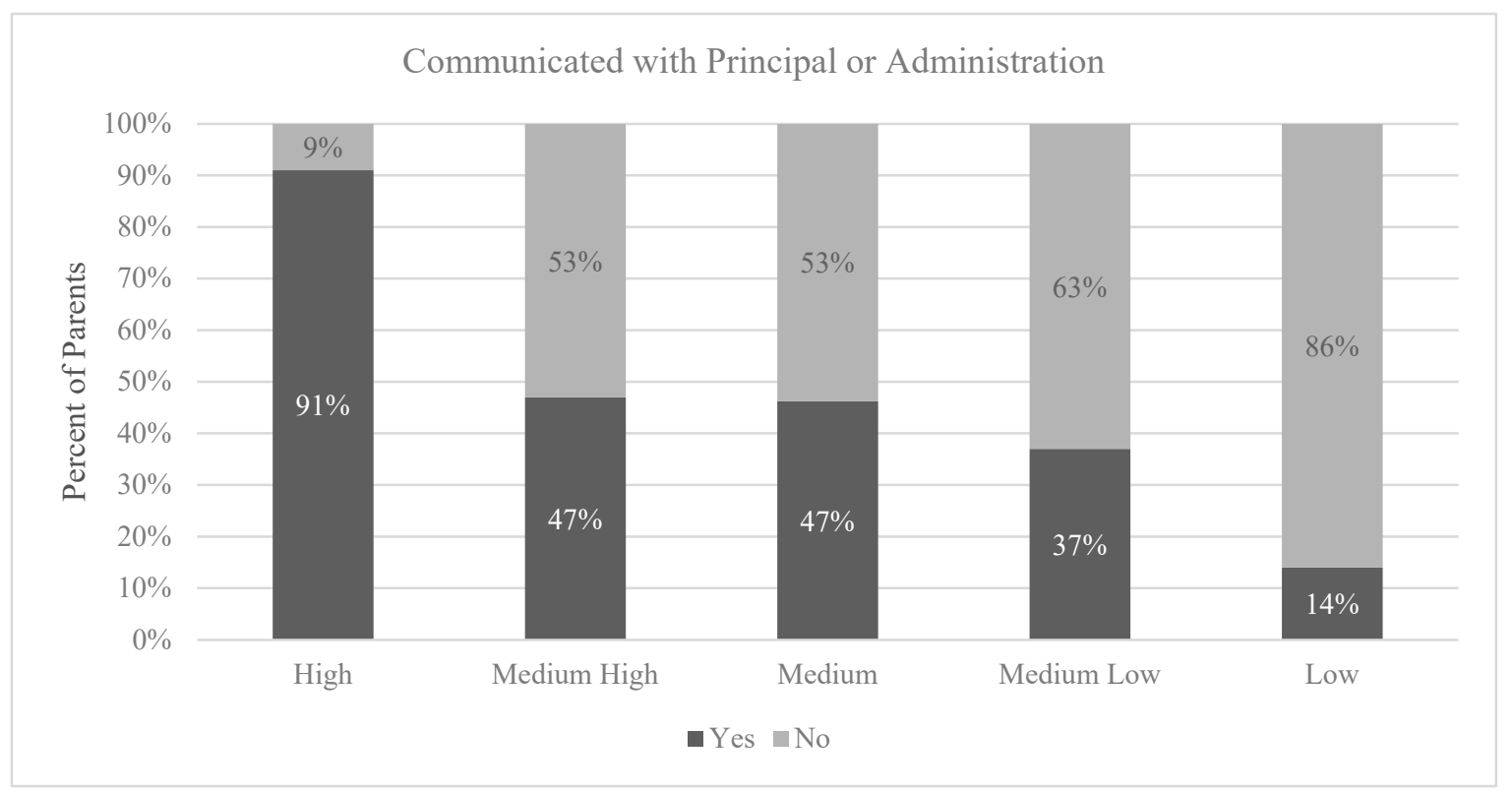

Figure 5. Percentage of Parents Who Regularly Communicate with Their Child's Principal or Administrator across Efficacy Rankings. Parental Efficacy Project 2011-2012 $(n=112)$.

Of course not all communication is the same. Nearly half of parents ranked as "low" ( 3 of 7 parents) kept contact in order to know how their child was doing and demonstrated high levels of involvement (if measured solely by communication) - they wanted to know what they could do to help their children, often when behavioral or academic issues had escalated. Tina McArthur from Lakeside Elementary, for example, had recently initiated a meeting with her daughter's teacher to discuss ways to improve her daughter's reading level. Although a busy parent of five kids, Tina exhibited behavior typical of a more involved parent. But this level of involvement was an isolated strategy for parents like Tina and a reaction to an already developed problem at school. Thus, if only measuring Tina in this way, she would be considered highly efficacious and involved if communication were the only survey item employed and Tina's more reactive strategy for involvement would have gone unmeasured.

And even though many of the low-efficacy parents had regular communication with their child's teacher, it was not as extensive, frequent or proactive as more efficacious parents, such as Heather Johnson, demonstrates:

I just kind of feel like if you're not meeting with your child's teacher that you kind of do feel like it's daycare for your child .... I don't want to speak for those parents that for whatever reason can't make it to those [meetings with teachers]. But, I want to know. I would want to know how my teacher was with my child and I would want to know how my child was doing and how he was interacting with people in his class and things he's struggling with or succeeding with. I want to know.

While Tina voiced a concern for her child's reading level, Heather exhibited a more intense and preventative motivation for interacting with the teacher. This type of communication was more apparent among the highly efficacious parents, especially at Eaglewood where over half of parents communicated with their teachers regularly. In contrast, Rebecca Smith, a mother of four at Lakeside Elementary, stated, "I assume if I don't hear anything [from the teacher], everything is good." This captured a low-efficacy view of involvementthat communicating with a teacher is the result of a problem to be addressed rather than a problem to prevent.

We also found that language and cultural barriers for the Latinx parents shaped teacher and administrator communication at Lakeside (see Figure 5): 
The teachers, I think they aren't accustomed to a Latina going, 'What do you want? How can I help?' I think they realize and they say, 'Yeah, of course.' I mean, they don't have to do anything, but [say], 'I don't know what to give you,' because that happened to me; they tell me, 'Yeah, yeah,' they wanted help but they weren't ready for me, so that I could teach [the kids], right, and so I think this is something important, right? That the teachers know [how to work with Latinx parents].

Figure 6 shows that volunteering in the classroom is a fairly good indicator of efficacy. And while most parents we found to be "highly efficacious" often volunteered in the classroom, we found some important exceptions. Marian Coleman, one highly-efficacious parent from Prairie Elementary, explained that she is a single mom with six children at home and finds volunteering in each child's classroom unfeasible: "Other times I have volunteered and stuff like that, but it has been really hard with this many kids in school. And with some of my kids, they have some serious asthma issues. So I kind of need to stay close to home". Although Marian is unable to participate in the classroom, she instead eats in the cafeteria every morning with her children and is able to talk to most of her children's teachers anyway.

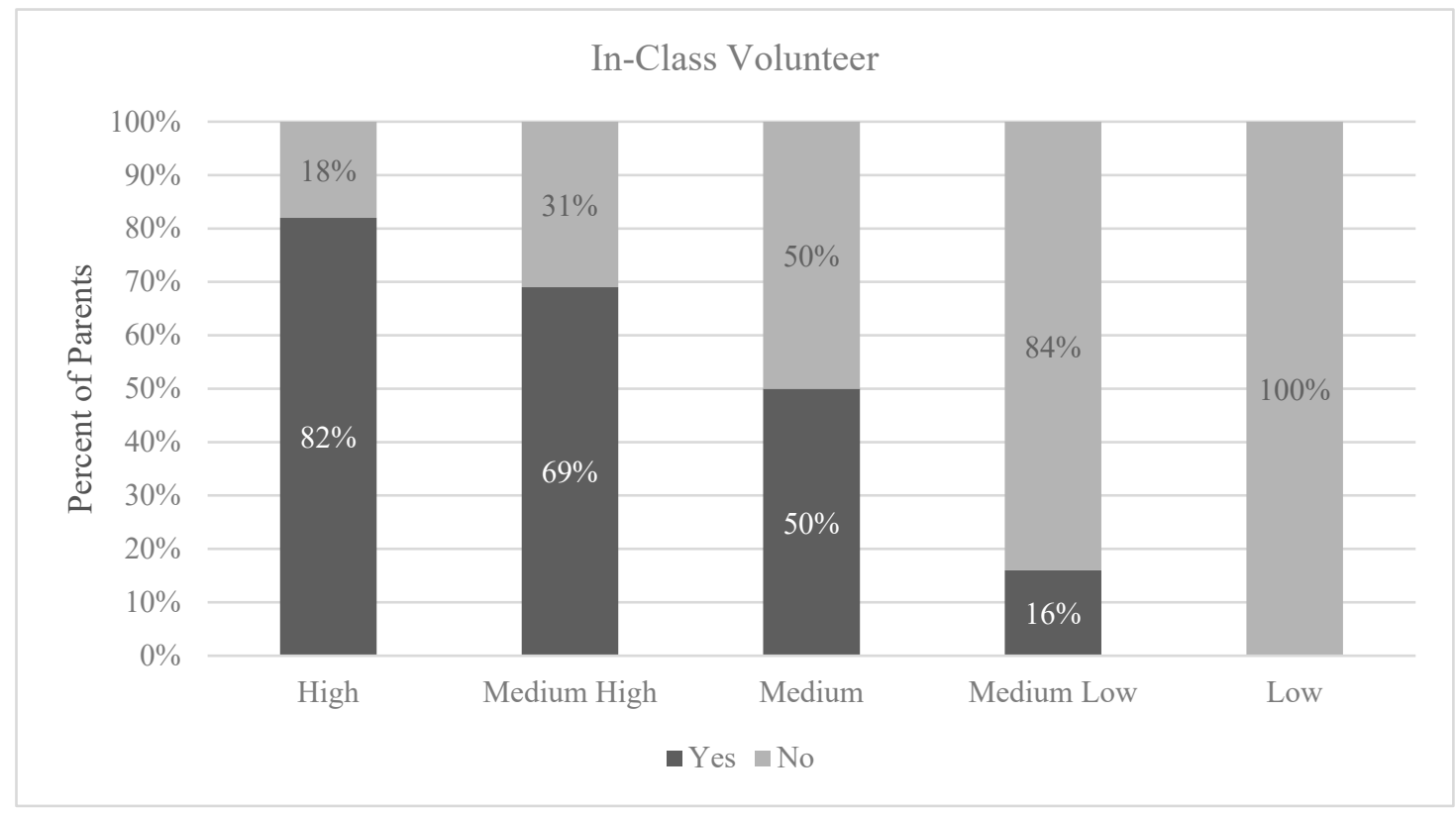

Figure 6. Percentage of Parents Who Regularly Volunteer in Their Child's Classroom across Efficacy Rankings. Parental Efficacy Project 2011-2012 $(n=112)$.

Complicating a more simple understanding of involvement, Mark Wright, the principal at Eaglewood, argues that volunteering in the classroom isn't everything. He looks beyond volunteering to determine if a parent is highly involved. When asked about the level of parental involvement in his school, he replied:

"Involved" is an interesting word that you use because the typical parent I think is involved-working with their kids, reading with their kids, doing homeworkI consider that involvement. You know, they come to back-to-school night, they come to parent-teacher conferences, and that kind of thing. But there are a [smaller] number of parents, and it's quite a bit smaller, that actually come to PTA Board Meetings and [are] actively involved in volunteering in their classes.

Principal Wright does not necessarily include in-class volunteering (or PTA involvement) on his checklist for an involved parent. Yet, we found that a total of $71 \%$ of parents we coded with high and medium-high efficacy (40 of 56) were present in the classroom. 
Thus, volunteering may not ingratiate parents with principals (at least at Eaglewood), it may still be one of the more effective ways to engage with teachers.

On the other end of the scale, only one parent whom we coded "low" on the parent efficacy scale volunteered in the classroom. There is a fairly clear match between the survey measure of volunteering in the classroom and our qualitative assessment of a more and less efficacious parent. For these kinds of parents, they often do so with limited resources, feeling the burden acutely. Fatima, an English-speaking Latinx mother at Prairie, described wanting to volunteer more, but she has a newborn and no babysitter. She explained:

The one time that I did volunteer, I was surprised at how large the class was. It was a little disappointing to be honest, and so I realize that she [the teacher] does need help. Just with —with this little one to take care of, it's just not been all that possible.

Furthermore, the actual involvement of parents can be influenced by cues from teachers. Five of the seven less-efficacious parents had kindergarten children who were enrolled at Lakeside Elementary where only one of the three kindergarten teachers even allows parents to volunteer in the classroom. One teacher explained, "I don't expect them to come in to help me. That's not their job". Another teacher stated, "I don't really have any expectations for involvement". A more forthcoming teacher confessed: "They [the parents] really want to but I haven't because usually they're a distraction ... and I feel like if I have another person, I'm going to go insane [laughs]".

As López (2001) argues, another barrier to volunteering may partly be due to cultural differences, which were prominent at Lakeside. One Latinx parent at Lakeside described her experience this way:

If the kids are behind, you have to talk with Jenny [the translator]... Lately I haven't asked for help with English because...the teachers are there, in English, well, I had to let go of my nerves ... and speak with them. [Laughs.] And so ... I don't need a translator because I understand them and I understand a lot but I, sometimes, with my nerves, it makes me speak poorly, and so I get embarrassed if I speak poorly ... they'll laugh at me.

Another parent, Maria, described her involvement in the classroom as conditional on the teacher's Spanish skills: "With my daughter's teacher that speaks Spanish, with her I volunteered... I don't sign up a lot because I don't know the language, [it's] because of that". This linguistic mismatch may mean that a parent highly involved in other respects may not be considered highly involved if volunteering in the classroom is a privileged survey measure, simply because it cannot account for language barriers and other cultural issues. Therefore, while a parent's efficacy level may have a lot to do with individual factors, it is important to consider how parent biographies and school contexts influence their reception when they become involved. We find that even the presence of the Spanish immersion program at Prairie Elementary creates a much different attitude towards the Latinx community-language and culture are considered an asset for the children's learning (at least among administrators); whereas being Latinx at Lakeside was often expressly stated as a burden.

But an immersion program does not erase all racial/ethnic tensions. We found that some parents at Prairie (especially those whose children are not enrolled in the immersion program) expressed some unease about the growing presence of Latinx children at the school:

We have some affluent families, and quite a few Hispanic families ... students are first or maybe second generation US citizens, and so a lot of them come from families that predominately speak Spanish. We have quite a few that come to kindergarten not speaking a whole lot of English. And, because of that, because of the huge range, I feel like my kids who are ahead are not challenged as much as I want them challenged. But I fully realize ... [well] the poor teachers are so overworked as it is. 
Surprisingly, this sentiment sounds almost the same as a parent from Lakeside:

This is a fifty percent Hispanic school, my children are white, and my daughterher class, actually, is I would guess seventy percent Hispanic, and the teacher is Hispanic, so my concern would be the language barrier. I mean, is she going to talk more-I mean obviously, I guess I don't really know because I'm not there in the class, but is she going to speak in Spanish because she has so many Spanish-speaking [classmates], and my daughter's going to be like "What's going on?" Or even just maybe implementing that a little bit, and to the teachings, so that she can understand, and I would love if she learned Spanish, it's just that that's been my main concern is that language barrier, worrying if she's not going to get the attention that she needs because of that, that Spanish-speaking.

But overall, staff and administration at Prairie are much more welcoming of parental involvement of Latinx parents than Lakeside. And of parents with children enrolled in the immersion program at Prairie, exposure to the Latinx community is considered a net asset (and an attraction to enroll their children) rather than a burden.

Finally, we compared survey measures of "Attendance and/or Participation at School Activities" with our qualitative coding of school-based parental efficacy. We found a high number of parents attending activities in our study (Figure 7). While $91 \%$ and $82 \%$ of high and medium-high parents attended activities (10 of 11 and 37 of 45, respectively), we found that a sizable number of other parents-two-thirds and over half of parents ranked as medium and medium-low respectively (20 of 30 and 12 of 19)-also attended. This is easily understood; most parents attended their school's open house. But this also reveals how nuanced this measure can be. A dichotomized survey-measure differentiating between "none or 1 event" vs. " 2 or more" would probably have yielded a better correspondence with our parental efficacy scores.

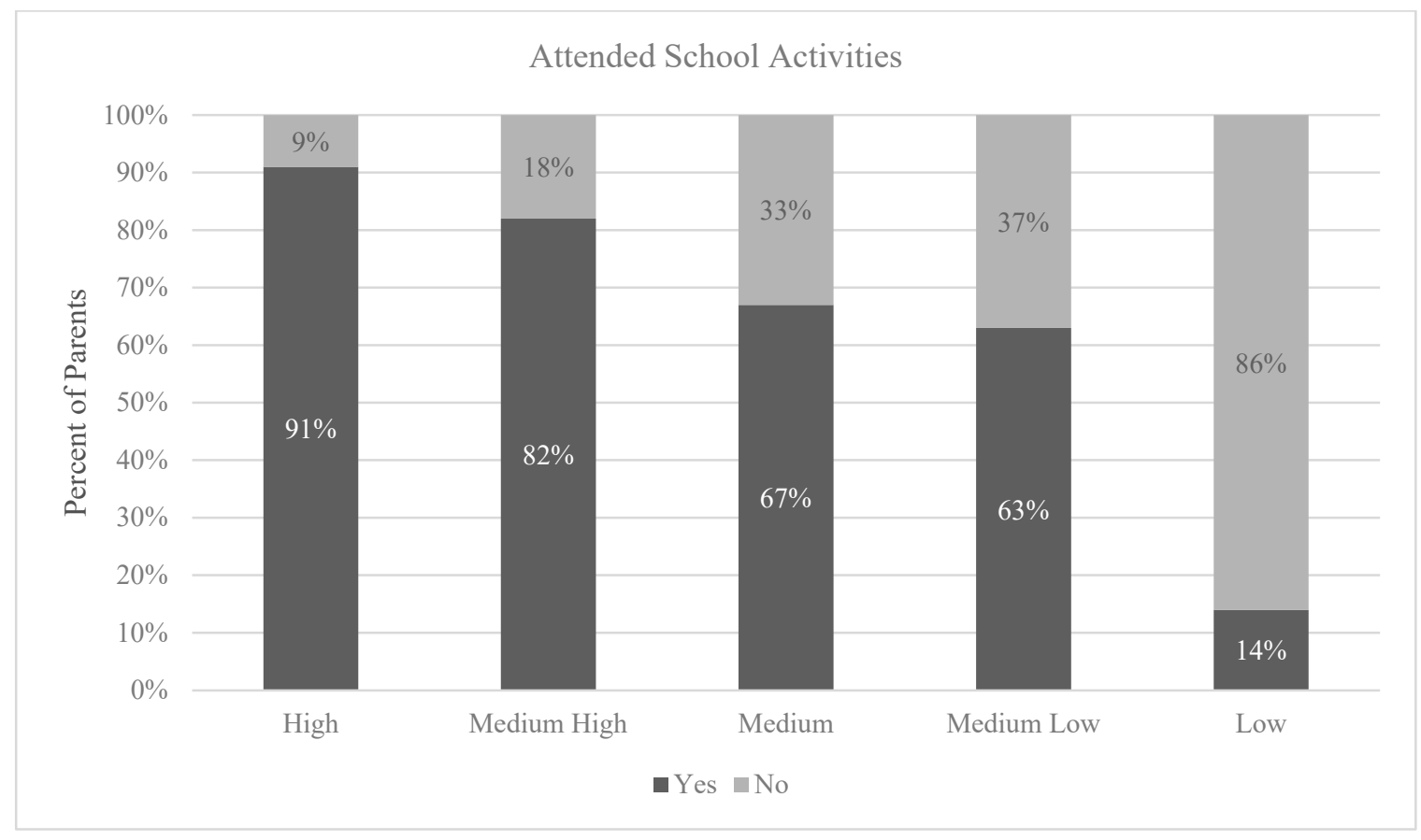

Figure 7. Percentage of Parents Who Regularly Attend Activities at Their Child's School across Efficacy Rankings. Parental Efficacy Project 2011-2012 $(n=112)$.

Many parents involved in school activities expressed a common sentiment-that they attended events to show support for their children. At Eaglewood, Denise Doyle, a mother of six whom we ranked as less efficacious, described why parents should attend school activities: 
I think in some ways they should participate in all school events, I mean, if it's planning it or showing up, you know what I mean, just being [there]. I think just being there with your kids is important [for] supporting [the] school.

Another parent stated:

You've got parent-teacher conferences that you kind of have to go to. Um ... but even the fun ones like the carnival, and skating, it's just fun to see other parents there, and know that you're supporting your kids, supporting the school.

Interestingly, although we found that many of the parents in our study wanted to be involved with their children's school activities, few parents created meaningful connections with teachers and other parents when they attended. For example, at a carnival night at Prairie Elementary, we observed that parents stayed with their children and followed their interests while some parents complained that they had had no meaningful interactions with other parents or teachers. School events were often too large, too programmed-or in the case of an event at an indoor skating rink, too dark and loud-to interact with others easily.

Overall, while some measures of parental involvement align well with parental efficacy, many do not. Context and parental dispositions shaped the frequency and interpretation of actual involvement in meaningful ways.

\section{Conclusions}

We challenge the concept of frequency measures of high and low parental involvement using the concept of parental efficacy (Bandura et al. 1996) and Swidler (1986) strategies of action. We focused on parents' proactive and reactive dispositions and efforts to develop a richer assessment of what school-based parental involvement means for parents and their children. When compared with quantitative measures of involvement, not all highly efficacious parents are involved in ways that are expected. In addition, even similar behaviors often have different meanings when employed by different parents. For example, communicating with a teacher could either be a preventative measure or a reaction to an already well-developed problem in ways unmeasured in conventional survey instruments.

Likewise, we find that many highly efficacious parents do not attend PTA meetings (but pay dues), while many Latinx parents would like to attend but do not because of language barriers. In this way, the measurement of PTA is likely a poor measure in survey data. As for parents engaged in communication with principals, one-quarter of low-efficacy parents communicated with teachers, but all highly efficacious parents did. When comparing survey measures of volunteering with our parent-efficacy measure, we find that volunteering is a good measure, especially when comparing the highest and lowest parents on the efficacy scale; none of the low-efficacy parents' volunteer and approximately $80 \%$ of highly involved parents do. Finally, we find that the majority of all efficacy types attend activities at the school with the exception of the lowest scoring parents. Thus, some measures underestimate efficacy, some approximate efficacy reasonably well, and others overestimate. If generalizable, these general results could be used to more confidently interpret national survey measures, but should also support the simultaneous accounting of how school contexts (such as language immersion), teacher attitudes regarding involvement (viewing parents as either an asset vs. burden), and engagement culture can shape parents' efficaciousness.

Generally, under the surface of simplified quantitative metrics, we show that there are a myriad of reasons why parents choose or choose not to become involved in school. We argue that a reappraisal of school-based parental involvement should better utilize the concept of parental efficacy-focused on the strategies that parents employ to problem solve. We promote a distinction between proactive dispositions and behaviors (anticipating problems, preventing problems) from reactive (addressing already developed problem behaviors in school). Without this distinction, parents engaging in similar levels of actual involvement would be indistinguishable even when their reasons for involvement vary significantly. 
Our results also show that more efficacious parents feel in charge of their child's education: "I'm the only person completely overseeing my child's education, that's my job." And less efficacious parents are more likely to engage when there are issues at school-“I assume if I don't hear anything [from the teacher], everything is good." We argue that researchers should adjust measures and add nuance to their models to reflect the complex currents involved in parent-school involvement, with items that include parent philosophies of involvement. Although we are not able to show this here, future research may find a more robust relationship to student outcomes as well.

Overall, we see parents doing more than "setting the stage" for academic success (Robinson and Harris 2013); they are directing children through the critical transition from "home child" to "school child" (Entwisle et al. 1997). Efficacy and strategies of action can be seen through the lens of parent philosophies, and if this were better operationalized in surveys, far more could be known about why parents become involved. This in turn may help reconcile inconsistencies in what we currently know about if and how involvement matters for children. For national assessments using survey data, we recommend combining measures of involvement (on Likert and frequency scales), parental efficacy, and school-based climate paired with the child's cognitive and behavior standing in schools to better understand the school/parent relationship. Also, measurements of parent philosophies could uncover the meaning and intent of their involvement in schools.

Although we feel that our results do not provide direct evidence for one policy approach over another, generally Jeynes (2018) recommendation to use a Dual Navigation Approach and Barton et al.'s Ecologies of Parental Engagement framework are most in line with what we find-that schools and teachers are highly influential in shaping parental efficacy, whether by providing opportunities, setting expectations, or creating barriers of actual involvement. Administrators and teachers can intentionally enact policies and practices to encourage parental engagement in ways that are most effective for their schools and classrooms, especially as they recognize the nuanced and holistic ways parents can be and choose to be involved.

Supplementary Materials: The following are available online at https:/ /www.mdpi.com/article/ 10.3390/socsci10050156/s1, Document S1: Parent Interview Guide, Document S2: Administrator Interview Guide, and Document S3: Parent Survey.

Author Contributions: Conceptualization, B.G.G., M.C. and M.M.; analyses, M.M. and B.H. (Brent Hutchison); data collection, M.M., A.G., M.C., C.A., B.H. (Bryce Hurst), D.S. and B.H. (Brent Hutchison). All authors have read and agreed to the published version of the manuscript.

Funding: This research was funded internally by the Office of Research and Creative Activities, Brigham Young University.

Institutional Review Board Statement: The study was conducted according to the guidelines of the Declaration of Helsinki, and approved by the Institutional Review Board of Brigham Young University (protocol code 110233, approved 27 May 2011).

Informed Consent Statement: Informed consent was obtained from all subjects involved in the study.

Conflicts of Interest: The authors declare no conflict of interest.

\section{Notes}

1 We should note that in a rebuttal to Robinson and Harris (2013), Hamlin et al. (2014) argued that Robinson and Harris (2013) over-simplified the issue by neglecting key meta-analyses (see Jeynes 2011).

2 Relatedly, Jeynes (2018) argues that school leaders employ a "Dual Navigation Approach" when encouraging parental involvement- they encourage both school-based components and home-based aspects of involvement with parents.

3 Barton et al. (2004) describe a related process as parental engagement (vs. parental involvement). They argue that a focus on what parents do (involvement) often obscures the meaning of parent behaviors (engagement) or the hows and whys.

$4 \quad$ Defined as parents having knowledge and resources that can be used for educational purposes. 
5 And although the data is dated, this is the only data collection project we know of that 1. collects in-depth information on parental involvement across a large number of families and 2. contains metrics to allow for the comparison of holistic assessments with conventional survey items.

6 We should note that "high levels" of parental efficacy is not necessarily a frequency of involvement in schools, but the potential and/or engagement of the parent.

\section{References}

Baker, Amy J. L. 1997. Improving Parent Involvement Programs and Practice: A Qualitative Study of Parent Perceptions. School Community Journal 7: 127-53.

Bandura, Albert, Claudio Barbaranelli, Gian Vittorio Caprara, and Concetta Pastorelli. 1996. Multifaceted Impact of Self-Efficacy Beliefs on Academic Functioning. Child Development 67: 1206-22. [CrossRef] [PubMed]

Barnyak, Natalie Conrad, and Tracy A. McNelly. 2009. An Urban School District's Parent Involvement: A Study of Teachers' and Administrators' Beliefs and Practices. School Community Journal 19: 33-58.

Barton, Angela Calabrese, Corey Drake, Jose Gustavo Perez, Kathleen St Louis, and Magnia George. 2004. Ecologies of Parental Engagement in Urban Education. Educational Researcher 33: 3-12. [CrossRef]

Belway, Shakti, Mishaela Duran, and Lela Spielberg. 2009. State Laws on Family Engagement in Education Reference Guide, National Parent Teacher Association. State Laws on Family Engagement in Education Reference Guide. Available online: http:/ / www.pta.org/3717.asp (accessed on 28 January 2014).

Calarco, Jessica McCrory. 2014a. Coached for the Classroom: Parents' Cultural Transmission and Children's Reproduction of Educational Inequalities. American Sociological Review 79: 1015-37. [CrossRef]

Calarco, Jessica McCrory. 2014b. The Broken Compass: Parental Involvement with Children's Education. Reviewed in Social Forces. Edited by Keith Robinson and Angel L. Harris. Cambridge: Harvard University Press, vol. 94, p. e106.

Castro, María, Eva Expósito-Casas, Esther López-Martín, Luis Lizasoain, Enrique Navarro-Asencio, and José Luis Gaviria. 2015. Parental involvement on student academic achievement: A meta-analysis. Educational Research Review 14: 33-46. [CrossRef]

Chen, Wei-Bing, and Anne Gregory. 2009. Parental Involvement as a Protective Factor during the Transition to High School. The Journal of Educational Research 103: 53-62. [CrossRef]

Child Trends. 2013. Parental Involvement in Schools. Available online: https://www.childtrends.org/?indicators=parentalinvolvement-in-schools (accessed on 12 February 2019).

Condron, Dennis J. 2009. Social Class, School and Non-school Environments, and Black/White Inequalities in Children's Learning. American Sociological Review 74: 683-708. [CrossRef]

Cucchiara, Maia B., and Erin M. Horvat. 2009. Perils and Promises: Middle-Class Parental Involvement in Urban Schools. American Educational Research Journal 46: 974-1004. [CrossRef]

Desforges, Charles, and Alberto Abouchaar. 2003. The Impact of Parental Involvement, Parental Support and Family Education on Pupil Achievements and Adjustment: A Literature Review. Report Number 433. London: Department of Education and Skills.

Domina, Thurston. 2005. Leveling the Home Advantage: Assessing the Effectiveness of Parental Involvement in Elementary School. Sociology of Education 78: 233-49. [CrossRef]

Duncan, Greg J., Chantekke J. Dowsett, Amy Claessens, Katherine Magnuson, Aletha C. Huston, Pamela Klebanov, Linda S. Pagani, Leon Feinstein, Mimi Engel, Jeanne Brooks-Gunn, and et al. 2007. School Readiness and Later Achievement. Developmental Psychology 43: 1428-46. [CrossRef] [PubMed]

Entwisle, Doris R., Karl L. Alexander, and Linda S. Olson. 1997. Children, Schools, and Inequality. Boulder: Westview Press.

Epstein, Joyce L. 1995. School/Family/Community Partnerships: Caring for the Children We Share. The Phi Delta Kappan 76: 701-12. [CrossRef]

Epstein, Joyce L., and Susan L. Dauber. 1991. School Programs and Teacher Practices of Parent Involvement in the Inner-City Elementary and Middle Schools. The Elementary School Journal 91: 289-305. [CrossRef]

Gibbs, Benjamin G., Lance D. Erickson, Mikaela J. Dufur, and Aaron Miles. 2015. Extracurricular associations and college enrollment. Social Science Research 50: 367-81. [CrossRef] [PubMed]

Gonzalez, Norma, Rosi Andrade, Marta Civil, and Luis Moll. 2006. Funds of Knowledge: Theorizing Practices in Households, Communities and Classrooms. London: Routledge.

Goodall, Janet. 2018. Learning-centred parental engagement: Freire reimagined. Educational Review 70: 603-21. [CrossRef]

Green, Christa L., Joan M. T. Walker, Kathleen V. Hoover-Dempsey, and Howard M. Sandler. 2007. Parents' Motivations for Involvement in Children's Education: An Empirical Test of a Theoretical Model of Parental Involvement. Journal of Educational Psychology 99: 532-44. [CrossRef]

Gubbins, Verónica, and Gabriel Otero. 2020. Determinants of parental involvement in primary school: Evidence from Chile. Educational Review 72: 137-56. [CrossRef]

Hamlin, Daniel, Keith Robinson, and Angel L. Harris. 2014. Broken Compass: Parental Involvement with Children's Education. Journal of Child and Family Studies 23: 1519-20. [CrossRef]

Hammersley, Martyn. 1992. What's Wrong with Ethnography? Methodological Explorations. London: Routledge.

Harpaz, Gal, and Yael Grinshtain. 2020. Parent-Teacher Relations, Parental Self-Efficacy, and Parents' Help-Seeking from Teachers About Children's Learning and Socio-Emotional Problems. Education and Urban Society 52: 1397-416. [CrossRef] 
Heckman, James. 2006. Skill Formation and the Economics of Investing in Disadvantaged Children. Science 312: 1900-2. [CrossRef] [PubMed]

Hill, Nancy E., and Diana E. Tyson. 2009. Parent Involvement in Middle School: A Meta-Analytic Assessment of the Strategies that Promote Achievement. Developmental Psychology 45: 740-63. [CrossRef]

Hill, Nancy E., Domini R. Castellino, Jennifer E. Lansford, Patrick Nowlin, Kenneth A. Dodge, John E. Bates, and Gregory S. Pettit. 2004. Parent Academic Involvement as Related to School Behavior, Achievement, and Aspirations: Demographic Variations across Adolescence. Child Development 75: 1491-509. [CrossRef] [PubMed]

Jackson, Kara, and Janine Remillard. 2005. Rethinking parent involvement: African American mothers construct their roles in the mathematics education of their children. School and Community Journal 15: 51-73.

Jeynes, William H. 2010. The Salience of the Subtle Aspects of Parental Involvement and Encouraging That Involvement: Implications for School-Based Programs. Teachers College Record 112: 747-74.

Jeynes, William H. 2011. Parental Involvement \& Academic Success. New York: Taylor \& Francis/Routledge.

Jeynes, William H. 2018. A practical model for school leaders to Encourage parental involvement and parental engagement. School Leadership and Management 38: 147-63. [CrossRef]

Keaton, Patrick. 2013. Documentation to the NCES Common Core of Data Local Education Agency Universe Survey: School Year 2011-12 (NCES 2014-100); U.S. Department of Education. Washington: National Center for Education Statistics. Available online: http:/ / nces.ed.gov / pubsearch/pubsinfo.asp?pubid=2014100 (accessed on 12 February 2019).

Kim, Sung Won, and Nancy E. Hill. 2015. Including fathers in the picture: A meta-analysis of parental involvement and students' academic achievement. Journal of Educational Psychology 107: 919-34. [CrossRef]

Lareau, Annette. 1989. Home Advantage: Social Class and Parental Involvement in Elementary Education. London: Falmer.

Lareau, Annette. 2000. Home Advantage: Social Class and Parental Intervention in Elementary Education, 2nd ed. Lanham: Rowman \& Littlefield Publishers Inc.

Lareau, Annette. 2011. Unequal Childhoods: Class, Race, and Family Life, 2nd ed. Berkeley: University of California Press.

Li, Angran, and Mary J. Fischer. 2017. Advantaged/disadvantaged school neighborhoods, parental networks, and parental involvement at elementary school. Sociology of Education 90: 355-77. [CrossRef]

López, Gerardo R. 2001. Redefining Parental Involvement: Lessons from High-Performing Migrant-Impacted Schools. American Educational Research Journal 38: 253-88. [CrossRef]

Luker, Kristin. 2008. Salsa Dancing into the Social Sciences: Research in an Age of Info-Glut. Cambridge: Harvard University Press.

McBride, Brent A., Sarah J. Schoppe, and Thomas R. Rane. 2002. Child Characteristics, Parenting Stress, and Parental Involvement: Fathers Versus Mothers. Journal of Marriage and Family 64: 998-1011. [CrossRef]

Park, Sira, and Susan D. Holloway. 2017. The effects of school-based parental involvement on academic achievement at the child and elementary school level: A longitudinal study. The Journal of Educational Research 110: 1-16. [CrossRef]

Park, Sira, Susan I. Stone, and Susan D. Holloway. 2017. School-based parental involvement as a predictor of achievement and school learning environment: An elementary school-level analysis. Children and Youth Services Review 82: 195-206. [CrossRef]

Pomerantz, Eva M., Elizabeth A. Moorman, and Scott D. Litwack. 2007. The How, Whom, and Why of Parents' Involvement in Children's Academic Lives: More is Not Always Better. Review of Educational Research 77: 373-410. [CrossRef]

Robinson, Keith, and Angel L. Harris. 2013. The Broken Compass. Cambridge: Harvard University Press.

Robinson, Keith, and Angel L. Harris. 2014. Parental Involvement Is Overrated. New York Times, April 12.

Shute, Valerie J., Eric G. Hansen, Jody S. Underwood, and Rim Razzouk. 2011. A review of the relationship between parental involvement and secondary school students' academic achievement. Education Research International 2011: 1-10. [CrossRef]

Singh, Kusum, Patricia Beckley, Paul Trivette, Timothy Z. Keith, Patricia Keith, and Eileen Anderson. 1995. The Effects of Four Components of Parental Involvement on Eighth-Grade Student Achievement: Structural Analysis of NELS-88 Data. School Psychology Review 24: 299-317. [CrossRef]

Strauss, Anselm, and Juliet M. Corbin. 1998. Basics of Qualitative Research: Techniques and Procedures for Developing Grounded Theory, 2nd ed. Thousand Oaks: SAGE Publications.

Swidler, Ann. 1986. Culture in action: Symbols and strategies. American Sociological Review 51: 273-286. [CrossRef]

Tazouti, Youssef, and Annette Jarlégan. 2019. The mediating effects of parental self-efficacy and parental involvement on the link between family socioeconomic status and children's academic achievement. Journal of Family Studies 25: 250-66. [CrossRef]

Turney, Kristin, and Grace Kao. 2009. Barriers to school involvement: Are immigrant parents disadvantaged? The Journal of Educational Research 102: 257-71. [CrossRef]

Wilder, Sandra. 2013. Effects of parental involvement on academic achievement: A meta-synthesis. Educational Review 66: $377-97$. [CrossRef]

Zinth, Kyle. 2005. Parental Involvement in Education. State Notes. Denver: Education Commission of the States. 